\title{
Appendicitis During Pregnancy
}

\author{
Lt Col S Chawla*, Lt Col Shakti Vardhan+, Brig SS Jog ${ }^{\#}$
}

\begin{abstract}
Acute appendicitis is the most common extra-uterine surgical emergency requiring immediate surgical intervention during pregnancy [1]. Six young female patients presented with appendicitis during May 1996 to May 2001 in different service hospitals. Five patients underwent emergency appendectomy successfully. Gestational age at presentation included first trimester in 4 patients, second trimester in 2 patients and none in third trimester. $84 \%$ had pathologically proven acute appendicitis. One patient presented with appendicular lump in first trimester, proved on ultra sonography examination, which was treated by Oshner Sherren regime and subsequently interval appendectomy was done in second trimester. No long term adverse maternal morbidity or mortality was reported. One patient had premature onset of labour and delivered. Natural history of acute appendicitis is not changed during pregnancy while gestational physiological changes obscure the accurate diagnosis of acute appendicitis.
\end{abstract}

Key Words : Acute appendicitis; Appendectomy; Pregnancy

MJAFI 2003; 59 : 212-215

\section{Introduction}

A ppendectomy is known as the most common non obstetrical operative procedure in a pregnant patient [2] with an estimated frequency of one case of acute appendicitis per 1500 pregnancy [3]. Pregnancy continues to obscure the accurate diagnosis of acute appendicitis due to gestational physiological changes [4]. Diagnostic delay increases the incidence of appendiceal perforation, hence increasing maternal and fetal morbidity and mortality. Acute appendicitis can occur at any time during gestation but is most common in the first and second trimester as seen in this study. The mortality of appendicitis during pregnancy is the mortality of delay [5]. Here we present 6 patients of appendicitis who presented during pregnancy out of 25 patients of acute abdomen in young pregnant ladies. Five of these underwent emergency appendectomy while one patient with appendicular lump was operated in second trimester at an interval of 6 weeks. We recommend aggressive surgical exploration in all patients with appendicitis before perforation and development of peritonitis. These complications are associated with increased risk of premature labour, abortion, maternal and fetal mortality $[6,7]$.

\section{Material and Methods}

Six patients of appendicitis during pregnancy managed between May 96 to May 2001 in various service hospitals are presented. Age group varied from 20 years to 34 years with median age of 26.4 years. Four patients presented during first trimester and 2 during second trimester. Five patients underwent emergency appendectomy on suspicion of appendicitis. One patient of appendicular lump who presented late was treated by conservative treatment and later on underwent interval appendectomy during second trimester. In all patients diagnosis was clinical, depending upon detailed history including presenting signs and symptoms. Laboratory findings were supportive. In one patient, ultra sonography of abdomen revealed appendicular lump. In all patients personal data, presenting signs and symptoms, laboratory findings, type of anaesthesia administered, operative incisions, histological diagnosis, hospital course, complications and perinatal mortality and morbidity was recorded.

\section{Results}

Six appendectomies were performed in pregnant patients, 5 as an emergency during first and second trimester of pregnancy (Table 1). There were 3 primis and rest multigravidas. Four patients presented during first trimester of pregnancy, rest during second trimester of pregnancy. The presenting symptoms and signs of acute appendicitis are enumerated in Table 2 and Table 3.

All patients presented with a history of right lower abdominal pain of 24 hours duration or less. One presented with a lump abdomen after history of 72 hours of pain abdomen. Four patients complained of nausea and vomiting while 3 had anorexia and distaste for food during the previous 24 hours. Four patients were febrile on examination and 4 had polymorphonuclear leucocytosis on laboratory analysis. One patient presented with appendicular lump, confirmed on ultrasound examination. In all 5 patients, appendectomy was performed through a muscle splitting incision over the point of maximum tenderness. General anaesthesia was administered in 4 patients and epidural anaesthesia in rest two. All patients received postoperative parenteral antibiotics for three days. Histology confirmed appendicitis in 5 patients $(83.4 \%)$. One patient had normal appendix on histopathology which was even confirmed at the time of surgery. The average period of hospitalization was 4.6 days (range 4-8 days). There was no wound infection, perforation or abscess formation. No maternal or perinatal

"Classified Specialist (Surgery), Military Hospital, Bhopal, ${ }^{+}$Associate Professor, Department of Obstetrics and Gynaecology, Armed Forces Medical College, Pune - 411 040, "Commandant, 166 Military Hospital, C/o 56 APO. 
Table 1

Summary of patients

\begin{tabular}{llllll}
\hline Age (Yrs) & Period of gestation & Management & Tocolytic agents & Postop period & Outcome of pregnancy \\
\hline 26 & $16 \mathrm{wks}$ & $\begin{array}{l}\text { Emergency } \\
\text { appendectomy }\end{array}$ & $\begin{array}{l}\text { Isoxsuprine } \\
\text { drip for 3 days }\end{array}$ & Uneventful & FTND \\
29 & $08 \mathrm{wks}$ & - do- & Inj HCG & Fever & FTND \\
& & - do- & $\begin{array}{l}\text { Isoxsuprine } \\
\text { drip for 3 days }\end{array}$ & Uneventful & LSCS \\
24 & $18 \mathrm{wks}$ & - -do- & -do- & FTND \\
28 & $24 \mathrm{wks}$ & nil & -do- & FTND \\
20 & $20 \mathrm{wks}$ & -do- & Pain abdomen & Premature baby \\
\hline
\end{tabular}

FTND - full term normal delivery LSCS - Lower segment casarean section

Table 2

Presenting symptoms in pregnant patients with preoperative diagnosis of appendicitis

\begin{tabular}{lccccc}
\hline Symptoms & \multicolumn{3}{c}{ Trimester } & Total & $\%$ \\
& 1 & 2 & 3 & & \\
\hline Abdominal pain & & & & 6 & 100 \\
$\quad$ Right iliac fossa & 2 & 1 & 0 & 3 & 50 \\
$\quad$ Right upper quadrant & 0 & 0 & 0 & 0 & 0 \\
$\quad 1 \quad$ Mid epigastric & 1 & 1 & 0 & 2 & 34 \\
$\quad$ Diffuse & 0 & 1 & 0 & 1 & 17 \\
Nausea & 2 & 2 & 0 & 4 & 67 \\
Vomiting & 1 & 2 & 0 & 3 & 50 \\
Anorexia & 1 & 2 & 0 & 3 & 50 \\
Diarrhea & 1 & 0 & 0 & 1 & 17 \\
Constipation & 0 & 1 & 0 & 1 & 17 \\
Fever & 2 & 2 & 0 & 4 & 67 \\
Lump abdomen & 1 & 0 & 0 & 1 & 17 \\
Dysuria & 0 & 1 & 0 & 1 & 17 \\
Vaginal bleeding & 0 & 1 & 0 & 1 & 17 \\
\hline
\end{tabular}

Table 3

Physical signs in pregnant patients with preoperative diagnosis of appendicitis

\begin{tabular}{|c|c|c|c|c|c|}
\hline \multirow[t]{2}{*}{ Signs } & \multicolumn{3}{|c|}{ Trimester } & \multirow[t]{2}{*}{ Total } & \multirow[t]{2}{*}{$\%$} \\
\hline & 1 & 2 & 3 & & \\
\hline \multicolumn{6}{|l|}{ Temperature } \\
\hline $99-101 \mathrm{~F}$ & 1 & 3 & 0 & 4 & 67 \\
\hline$>101.5 \mathrm{~F}$ & 1 & 1 & 0 & 2 & 33 \\
\hline \multicolumn{6}{|l|}{ Pulse } \\
\hline$<100 / \mathrm{min}$ & 1 & 3 & 0 & 4 & 67 \\
\hline$>100 / \mathrm{min}$ & 1 & 1 & 0 & 2 & 33 \\
\hline Abdominal tenderness & & & & 6 & 100 \\
\hline Right iliac fossa & 2 & 1 & 0 & 3 & 50 \\
\hline Right upper quadrant & 0 & 0 & 0 & 0 & 0 \\
\hline Mid epigastric & 0 & 2 & 0 & 2 & 33 \\
\hline Diffuse & 0 & 1 & 0 & 1 & 17 \\
\hline Rectal/pelvic tenderness & 2 & 2 & 0 & 4 & 67 \\
\hline Rebound tenderness & 1 & 4 & 0 & 5 & 83 \\
\hline Abdominal guarding & 2 & 3 & 0 & 5 & 83 \\
\hline Appendicular lump & 1 & 0 & 0 & 1 & 17 \\
\hline Decreased bowel sounds & 1 & 3 & 0 & 4 & 67 \\
\hline Psoas test & 2 & 2 & 0 & 4 & 67 \\
\hline Obturator test & 2 & 1 & 0 & 3 & 50 \\
\hline Rovsing's sign & 0 & 2 & 0 & 2 & 34 \\
\hline
\end{tabular}

mortality occurred in this study due to timely and aggressive surgical intervention. One patient had premature onset of labour at 35 weeks and delivered an alive female baby.

\section{Discussion}

The pregnant patient with appendicitis presents unique challenges to both the surgeon and gynaecologist. First, the diagnosis of pregnancy needs confirmation at the time of presentation. Secondly, the anaemia and physiological changes that normally occur during pregnancy alter the physical findings and laboratory values that are often used for diagnosis of appendicitis. Thirdly, cases of appendicitis that occur during pregnancy can produce significant morbidity and mortality if not promptly identified and treated. Fourthly, the treating surgeon has limitations in the use of certain diagnostic procedures because of possible teratogenicity like intravenous pyelography and X-ray abdomen. Finally the surgeon is treating two patients simultaneously, the mother and the fetus and must be aware of the potential effects of treatment on both patients at all times [8].

Recent studies have shown a preponderance in the second trimester, with approximately $30 \%$ of cases occurring during the first trimester, $45 \%$ during the second trimester and $25 \%$ during the third trimester, labor, or puerperium [9]. But in our study $60 \%$ of cases were seen during the first trimester and rest during the second trimester. The incidence of appendicitis during pregnancy is equal to non pregnant women of the same age [10]. Appendicitis occurs more frequently during the first two trimesters than the third, as was seen in this study.

During the first six months of pregnancy, symptoms of appendicitis are same as in non pregnant woman. But still, these can be confused with morning sickness and ectopic pregnancy during first trimester and twisted ovarian cyst in early second trimester [11]. During third trimester, patient complains of pain, higher and more lateral in the abdomen or right flank as enlarged uterus 
Table 4

Laboratory findings in pregnant patients with preoperative diagnosis of appendicitis

\begin{tabular}{lccccc}
\hline Laboratory values & \multicolumn{3}{c}{ Trimester } & Total & $\%$ \\
& 1 & 2 & 3 & & \\
\hline Leukocyte count & & & & & \\
$<10,000 / \mathrm{mm} 3$ & 2 & 0 & 0 & 1 & 33 \\
$10,000-15,000 / \mathrm{mm} 3$ & 1 & 2 & 0 & 3 & 50 \\
$>15,000 / \mathrm{mm} 3$ & 0 & 2 & 0 & 2 & 33 \\
Polymorphs $>80 \%$ & 3 & 1 & 0 & 4 & 67 \\
Urinalysis & & & & & \\
$\quad$ Pyuria & 1 & 2 & 0 & 3 & 50 \\
$\quad$ Bacteriuria & 1 & 2 & 0 & 3 & 50 \\
\hline
\end{tabular}

Table 5

Conditions mimicking appendicitis

\begin{tabular}{ll}
\hline Nonobstetric & Obstetric \\
\hline Pyelonephritis & Ectopic pregnancy \\
Cholecystitis & Threatened abortion \\
Pancreatitis & Abruptio placentae \\
Gastroenteritis & Preterm labour \\
Renal calculus & Round ligament pain \\
Intestinal obstruction & Degenerating uterine fibroid \\
Salpingitis & Chorioamnionitis \\
Mesenteric adenitis & Adnexal torsion \\
\hline
\end{tabular}

leads to displacement and lateral rotation of caecum and appendix. Positional changes of appendix as the pregnancy progresses are shown in Fig 1. The appendix remains in the right iliac fossa during the first trimester, moves to the pelvic brim during second trimester and reaches the lower right upper quadrant in the third trimester. Incidence of perforated diffuse peritonitis is high as infection cannot be localized due to uterine contractions and inability of the omentum to reach inflamed appendix. Guarding and rigidity are difficult to elicit in third trimester due to stretched abdominal muscles [12] Laboratory examination of blood and urine may be of little diagnostic aid (Table 4). Premature labour is seen in about half of women but was seen only in one of the patients in the present study. Fetal mortality is high due to septicaemia and prematurity. Obstetric and nonobstetric conditions mimicking acute appendicitis are enumerated in Table 5. These conditions should be ruled out while evaluating a patient of acute appendicitis.

Appendectomy should be performed on suspicion of the presence of appendicitis just as if pregnancy was not present [13]. If surgery is performed before the appendix ruptures, surgery does not disturb the pregnancy as was seen in this study. Once acute appendicitis is suspected in a pregnant patient, we recommend a close working relationship between surgeon, obstetrician and anaesthesiologist to minimize maternal and fetal morbidity and mortality [14]. Hence, early operation

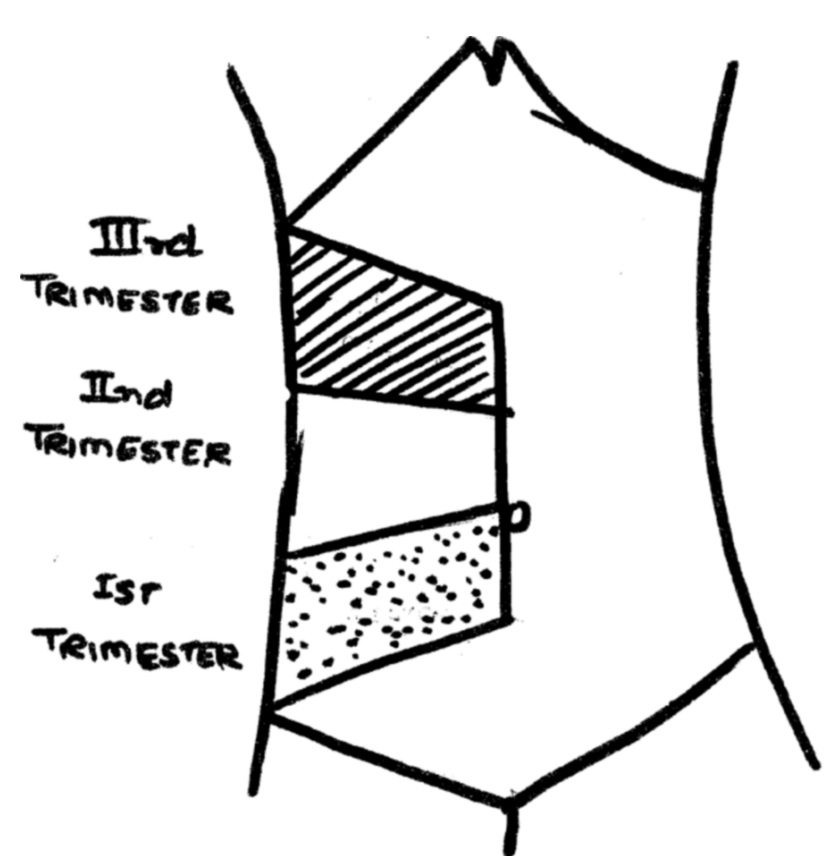

Fig. 1 : Positional changes of appendix during pregnancy

for acute appendicitis should be performed whenever diagnosis is considered. Due to difficulty in the diagnosis of acute appendicitis in a pregnant patient, a higher negative laparotomy rate in these patients $(20-35 \%)$ is acceptable as compared to non pregnant patients (15\%). Hence, an aggressive surgical approach is justified. Incidence of perforation increases to $66 \%$ if there is delay in removing the appendix after diagnosis has been made, leading to grave consequences. The mortality of appendicitis in pregnancy is due to delayed diagnosis and operation [15]. There is often a tendency amongst obstetricians to relate cases of pain abdomen during pregnancy with the genital organs leading to late referrals and diagnosis. Maternal mortality from appendicitis is now almost zero, and is nearly always associated with unconfirmed perforation and peritonitis. Overall fetal mortality reported is $2-8.5 \%$ but increases to $35 \%$ in perforation and peritonitis $[16,17]$. Preterm labour is a problem, but preterm delivery is rare [18].

To conclude, appendicitis in pregnancy has always been a difficult problem compared to nonpregnant patients. Early appendectomy is the secret of success and is the treatment of choice recommended at all stages of pregnancy [22]. Factors affecting the type and location of incision in a patient with acute appendicitis are shown in Table 6. Appendectomy is usually performed by a muscle splitting incision over the point of maximum tenderness in the right lower quadrant. Location of the incision is modified with the more advanced gestational age towards right upper quadrant at the point of maximum tenderness. However, if appendix ruptures or abscess forms, emergency exploration by a midline or right paramedian abdominal 
Table 6

Factors selecting the type and location of incision

Uterine size

Gestational age

Type of abdominal pain

Location of abdominal pain

Presence of peritonitis

incision is recommended in the presence of diffuse peritonitis. There is a definite role of diagnostic laparoscopy in patients with right lower quadrant abdominal pain with positive pregnancy test, equivocal evidence of uterine enlargement and in patients with past history of menstrual irregularity or pelvic inflammatory disease [19]. Laparoscopy can be diagnostic and will reduce rate of negative laparotomy and rules out ectopic pregnancy or salpingitis. Computed tomography of the appendix should not be considered during pregnancy because of radiation exposure to the fetus [20]. When the diagnosis of appendicitis is made, laparoscopic appendectomy may be done in early pregnancy and is associated with negligible maternal and fetal complications. The use of helical computed tomography in pregnancy has been brought out recently [21]. However, this was not possible due to lack of facilities in our set up.

Tocolytic agents have been used successfully if premature contractions set in as was done in 4 patients in this study. Isoxuprine drip was continued for three days as a precautionary measure to stall preterm labour with close monitoring of pulse and blood pressure. Isoxuprine causes peripheral vasodilation causing pooling of blood resulting in tachycardia and hypotension. Due care was given to monitor the drip to avoid these complications. Inj HCG was used empirically in one patient during first trimester pregnancy keeping in mind its utility in cases of threatened abortion during first trimester. It was used with the idea of offering the best to the patient although the basis of its use remains empirical.

\section{References}

1. Horowitz MD, Gomej GA. Santiesteban R, Burkett G. Acute appendicitis during pregnancy. Arch Surg 1985;120:1362-8.

2. Robert A, DeSantis, Ernest G. Appendectomy during pregnancy. A survey of two Army Medical activities. Military Medicine 1999;164:671-4.

3. Mazze RI, Kallen B. Appendectomy during pregnancy. A Swedish Registry study of 778 cases. Obstet Gynaecol
1991;77:835-40.

4. Fallon WF, Newman JS, Fallon GL, Malangoni MA. The surgical management of intra abdominal inflammatory conditions during pregnancy. Surg Clin North Am 1995;75:1531 .

5. Tarraza HM, Moore RD. Causes of acute abdomen and the acute abdomen in pregnancy. Surg Clin North Am 1997;77:1385-94.

6. Lim HK, Bae SH, Seo GS. Diagnosis of acute appendicitis in pregnant women : value of sonography. Am J Roentogenol 1992;159:539-42.

7. Manmoodian S. Appendicitis complicating pregnancy. South Med J 1992;85:19-24.

8. Kort B, Katz VL, Watson WJ. The effect of nonobstetric operation during pregnancy. Surg Obstet Gynecol 1993;177:371-6.

9. Firstenberg MS, Malangoni MA. Gastrointestinal surgery during pregnancy. Gastroenterol Clin North Am 1998;27:7388.

10. Velanovich V, Harkabus MA, Tapia FV, Gusz JR, Vallance SR. When it is not appendicitis. Am Surg 1998;64:7-11.

11. Sharp HT. Gastrointestinal surgical conditions during pregnancy. Clin Obstet Gynaecol 1994;37:306-15.

12. Masters K, Levine BA, Gaskill HV, Sirinek KR. Diagnosing appendicitis during pregnancy. Am J Surg 1984;148:768-71.

13. Al-Mulhim AA. Acute appendicitis in pregnancy. Int Surg 1996;81:295-302.

14. Tamir IL, Bongard FS, Klein SR. Acute appendicitis in a pregnant patient. Am J Surg 1990;160:571-6.

15. Mayer IE, Hussain H. Abdominal pain during pregnancy. Gastroenterol Clin North Am 1998;27:1-36.

16. Doberneck RC. Appendectomy during pregnancy. Am Surg 1985;51:265-73.

17. Weingold AB. Appendicitis in pregnancy. Clin Obstet Gynecol 1983;26:801-10.

18. Mourad J, Elliot JP, Eridason L. Appendicitis in pregnancy : new information that contradicts long held clinical beliefs. Am J Obstet Gynaecol 2000;182:1027-9.

19. Spirtos NM, Eisenkop SM, Spirtos TW. Laparoscopy - A diagnostic aid in cases of suspected appendicitis. Its use in women of reproductive age. Am J Obstet Gynecol 1987;156:90-4.

20. Rao PM, Rhea JT, Novelline RA, Mostfavi AA, McCabe CJ. Effect of computed tomography of the appendix on treatment of patients and use of hospital resources. N Engl J Med 1998;338:141-7.

21. Castro MA, Shipp TD, Castro EE, Ouzounian J, Rao P. The use of Helical computed tomography in pregnancy for the diagnosis of acute appendicitis. Am J Obstet Gynaecol 2001;184:954-60.

22. Calhoun BC. Gastrointestinal disorders in pregnancy. Obstet Gynaecol Clin North Am 1992;19:733-44. 